\title{
Influences of Shield Tunnel Construction of Double-Line Metro on Settlement of Existing Pipeline
}

\author{
X.M. Guan ${ }^{1,2}$, G. Wang ${ }^{1}$, X.C. Wang ${ }^{*}$, J.Y. An ${ }^{3}$, H.B. Lei ${ }^{3}$ and W.Z. Guan ${ }^{4}$ \\ ${ }^{1}$ School of Civil Engineering, Qingdao University of Technology, Qingdao 266033, China \\ ${ }^{2}$ Center for Transportation Research. The University of Tennessee, Knoxville 37919, USA \\ ${ }^{3}$ China Construction Second Engineering Bureau Ltd., Beijing 100160, China \\ ${ }^{4}$ School of Civil engineering, Beijing Jiaotong University, Beijing 100044, China
}

Received 7 January 2020; Accepted 15 March 2020

\begin{abstract}
To investigate the influences of the shield tunnel construction on the settlement of the existing pipeline, based on a double-line tunnel underpass pipeline of No. 3 Zhengzhou Metro Line, a three-dimension numerical model was established by using FLAC3D software. The model was verified by the monitoring data and the influences of the shield tunnel construction on ground surface and pipeline under different cases were studied. Results show that the settlements of simulation are consistent with the measured data. When the shield tunnel moving forward, the settlements of the ground surface above the excavation face and the pipeline continue to increase. When the distance away from the excavation face is $24 \mathrm{~m}$, that settlements no longer increases, and the final settlements are about $-9.3 \mathrm{~mm}$ and $-12.8 \mathrm{~mm}$, respectively. During the construction of the left line tunnel, the maximum principal stress increases continuously. When the length of the excavation exceeds $18 \mathrm{~m}$, the maximum principal stress is stable at about $0.57 \mathrm{MPa}$. While the influence of construction of the right line tunnel is always little. The settlements of the ground surface and pipeline are minimum when the right tunnel is constructed after the left tunnel being completed. If the two tunnels were needed to excavate simultaneously, the right tunnel was better constructed after the left tunnel being excavated larger than approximately 4 times diameter of the tunnel. The obtained conclusions can provide the reference to the similar tunnel engineering.
\end{abstract}

Keywords: Double-line tunnel, pipeline, settlement, maximum principal stress

\section{Introduction}

With China's rapid economic development, urbanization process is getting faster and faster, and the rapid growth of population and vehicles is leading to more and more serious urban traffic congestion and inconvenience of living and travel for residents in recent years. Therefore, more and more cities begin to develop and utilize the underground space and accelerate the subway construction in order to solve the problem of urban traffic congestion.

However, large-scale subway construction will inevitably disturb the surrounding strata, which will result in the changes of strata displacement and stress [1-3]. Since the stratum disturbance is transmitted upwards, which will adversely affect the surrounding structures, especially the buried pipelines. If the soil disturbance is too large, it may cause the pipeline in the stratum too large deformation and crack, which will lead to inestimable property and economic loss [4-5].

To investigate the influences of the shield tunnel construction on the settlement of the existing pipeline, it is important to research the safety risk of metro construction for adjacent pipelines, and propose the countermeasures of metro construction for the adjacent pipelines.

*E-mail address: xcwang2008@foxmail.con

ISSN: 1791-2377 @ 2020 School of Science, IHU. All rights reserved.

doi:10.25103/iestr. 132.20

\section{State of the art}

At present, there are many prediction methods of ground subsidence induced by shield tunnel excavation, such as computational method, numerical analysis, semi-empirical method, random medium theory, model test and fuzzy theory method [6-8]. Sagaseta derived the analytical solution of three-dimension surface deformation without drainage by the soil loss being equivalent to a cylinder [9]. Loganathan $\&$ Poulos proposed the analytical solution of two-dimension tunneling-induced ground movement in clays based on the Sagaseta's theory [10]. Based on the calculation of soil deformation caused by ground loss in double-line parallel shield tunnel (DLPST) construction, the three-dimension calculation of the soil deformation caused by DLPST was proposed [11]. Considering the impact of the first shield construction on the second one's, the total soil deformation induced by DLPST was obtained by calculating soil settlement caused by both the first and the second shield tunnel construction [12]. Chen et al. analyzed the pore pressure in the soils, ground subsidence, subsurface settlement, and horizontal displacement during shield advancement, they found that the soil settlement decreased from the crown of the excavation face to the ground surface and to the invert of the excavation face in the transverse direction [13]. Hisatake proposed a method for analysis of the ground settlements caused by tunneling with particular reference to the "buoyancy" effect [14]. Ouyang \& wang 
obtained the calculation formula of bending moment, stress, strain and radius of curvature of pipeline caused by tunnel construction based on Winkler foundation model using Loganathan formula [15]. Zhang et al. put forward the simplified theoretical method of the response of the pipeline with discontinuous rigidity under the condition of tunnel excavation based on the improved Winkler foundation model [16]. Klar et al. studied the influence of the tunnel construction on pipeline considering the weakening effect of soil stiffness and the nonlinearity interaction of soil and pipeline based on Mindlin solution [17, 18]. Li \& wang proposed a safety evaluation method for the flexible and rigid pipelines based on deformation controlling [19]. Wu et al. studied the safety risk management standard of the metro construction for the adjacent pipelines, and they established the safety risk management system of the metro construction for the adjacent pipelines [20].

Since most researches foucsing on the ground settlement induced by shield tunnel construction of double-line metro or pipeline settlement caused by single tunnel construction, to reduce the pipeline settlemnt and ensure the stability of the pipeline, it is necessary to study the influences of different construction schemes on the response of pipeline to propose the reasonable construction scheme.

Based on the running tunnel project between Erqi Square station and Shuncheng Street station of No. 3 Metro Line of Zhengzhou, combining the actual engineering geology and hydrology, the three-dimension numerical model of soil, pipeline and tunnel was established by using FLAC3D. The rationality of the numerical model was verified by the field monitoring data. Then the construction process of the shield tunnel and different construction cases were simulated. The influences on the settlement of the surface and pipeline were analyzed during the shield tunnel construction.

The rest of this study is organized as follows. Section 3 gives the relevant engineering background and discribes the computational model. Section 4 presents the results and discussion, and finally, the conclusions are summarized in Section 5.

\section{Methodology}

\subsection{Engineering background}

The total length of No. 3 Zhengzhou subway is about 31.3 $\mathrm{km}$. There are 25 stations with an average distance of 1.29 $\mathrm{km}$. The stratum distribution along the line is stable, and the stratum among the depth range of $65 \mathrm{~m}$ is mainly composed of clay, silt and sand deposited in Quaternary. The running tunnel was constructed by shield tunneling method. Due to the local calcareous cemented stratum with the strength of $20 \mathrm{MPa}$, it is difficult to control the shield parameters such as direction, speed and earth pressure during shield tunneling advancing. Because the effect of synchronous grouting is not good, it is very prone to cause the segment floating up and the ground surface sinking too much.

Particularly, the left line tunnel passed through the DN1200 sewage pipe at the mileage from ZDK16 $+168.5 \mathrm{~m}$ to $+375 \mathrm{~m}$. The distance between the pipe and tunnel varied with the location of the tunnel. From the mileage of ZDK16 $+168.5 \mathrm{~m}$ to $+300 \mathrm{~m}$. The vertical distance between the top of the left line tunnel and the sewage pipe was from $2 \mathrm{~m}$ to 6 $\mathrm{m}$. From the mileage of ZDK16 $+300 \mathrm{~m}$ to $+375 \mathrm{~m}$, the vertical distance between the pipe and tunnels was within 2 $\mathrm{m}$. The inner diameter of the sewage pipe was $1.2 \mathrm{~m}$. The thickness of pipe was $0.2 \mathrm{~m}$ and the outer diameter was 1.6 $\mathrm{m}$. It was composed of $\mathrm{C} 50$ concrete and steel bar with the diameter of $5 \mathrm{~mm}$ with a strength of $37.9-53.3 \mathrm{MPa}$. The length of a single section was $2 \mathrm{~m}$. The joint between the pipes was connected by a gasket.

\subsection{Computational model}

\subsubsection{Model establishment}

There is a sewage pipe above the left line tunnel. The average distance between the top of the tunnel and the ground surface is about $12.9 \mathrm{~m}$. The axes distance between the two tunnels is $13 \mathrm{~m}$. The inner diameter of the tunnel is $5.5 \mathrm{~m}$ and the outer diameter is $6.2 \mathrm{~m}$ (specified by $\mathrm{D}$ in the paper). The inner diameter and outer diameter of the sewage pipe are $1.2 \mathrm{~m}$ and $1.6 \mathrm{~m}$, respectively. The bottom of the pipeline is about $9.03 \mathrm{~m}$ away from the ground surface. The top of the left tunnel is about $3.87 \mathrm{~m}$ away from the bottom of the sewage pipe. The relative position of the sewage pipe and the tunnel in the model is shown in Fig. 1.

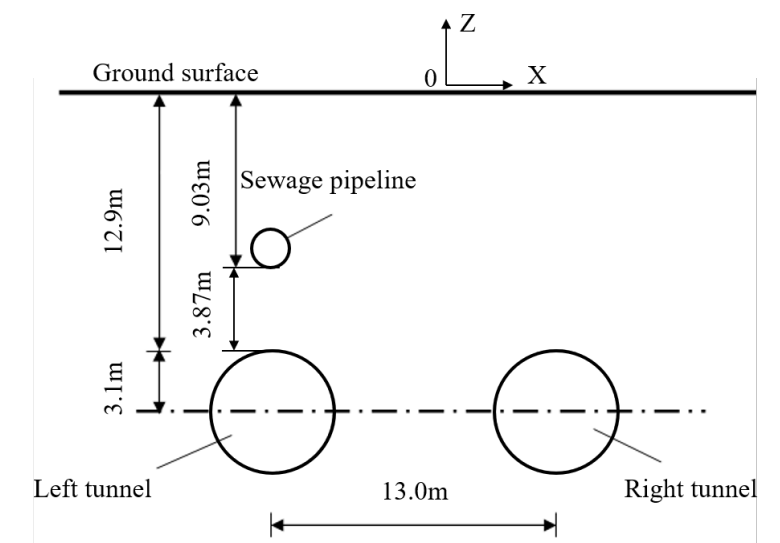

Fig. 1. The model of the double-line metro and pipeline.

The assumptions of the model are as follows.

(1) Each soil layer was isotropic and homogeneous material, distributed in horizontal layer, the initial stress only considering its own gravity of stratum.

(2) Synchronous grouting was simulated by using the equivalent layer method, and the mechanical parameters of the grouting reinforcement soil were properly simulated by increasing original soil parameters.

(3) Regardless of the effect of the pipeline joint, the stiffness of the pipeline and the joint were the same value without internal pressure.

(4) The friction between the shield machine and surrounding soil was not considered during shield tunnel advancing.

To reduce the influence of the boundary size effect, the length, width and height of the model is $82 \mathrm{~m}, 69 \mathrm{~m}, 50 \mathrm{~m}$, respectively, which is all larger than 4 times diameter of the tunnel. The boundary of the upper surface of the model is free. The horizontal constraints were applied all around the model. The vertical and horizontal constraints were applied at the bottom. The diagram of the model was shown in Fig. 2.

There are 230000 elements in the model. The MohrCoulomb model was used in the calculation of soil mass, and the elastic model was used in the tunnel lining segment and sewage pipe. The calculation parameters of the model were given in Table 1. 


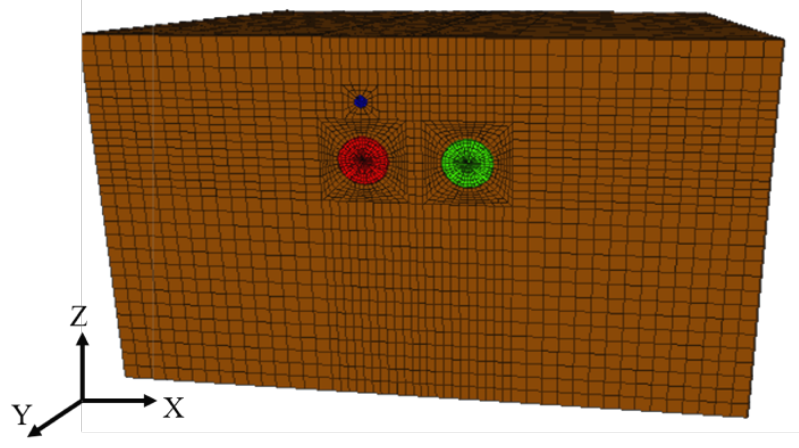

Fig. 2. Numerical model of the double-line metro and pipeline.

Table 1. Parameters of each material

\begin{tabular}{c|c|c|c|c|c|c}
\hline Name & $\begin{array}{c}\boldsymbol{\rho} \\
\left(\mathbf{k g} / \mathbf{m}^{\mathbf{3}}\right)\end{array}$ & $\begin{array}{c}\boldsymbol{E} \\
(\mathbf{M P a}\end{array}$ & $\boldsymbol{\mu}$ & $\begin{array}{c}\boldsymbol{c} \\
\mathbf{( k P a )}\end{array}$ & $\begin{array}{c}\boldsymbol{\varphi} \\
\left({ }^{\circ}\right)\end{array}$ & $\boldsymbol{K}$ \\
\hline sandy silt & 1750 & 2 & 0.16 & 9 & 12 & 0.19 \\
clayey silt & 1900 & 7.6 & 0.32 & 14 & 23.5 & 0.46 \\
silty sand & 2050 & 20 & 0.28 & 0 & 28 & 0.38 \\
fine sand & 2070 & 25 & 0.26 & 0 & 32 & 0.35 \\
silt clay & 2010 & 5.8 & 0.29 & 29.5 & 20.5 & 0.4 \\
slurry & 1500 & 2 & 0.2 & - & - & - \\
sewer & 2500 & 25000 & 0.17 & - & - & - \\
lining & 2600 & 35000 & 0.2 & - & - & - \\
segment & & &
\end{tabular}

Note: $\rho$ is the density, $E$ is the elastic modulus, $\mu$ is the Poisson's ratio, $c$ is the cohesive, $\varphi$ is the internal friction angle, $K$ is the coefficient of earth static pressure.

\subsubsection{Simulation method of shield tunnel construction}

There are three steps during the process of the shield tunnel construction: soil excavation, lining segment installation, and shield tail synchronous grouting, in which the soil excavation and lining segment installation are carried out alternately until the whole tunnel excavation is completed. The excavation of the soil in tunnel is simulated by the Null model, and the lining segment and the slurry layer are simulated by the elastic model. The parameters of the slurry layer are determined according to the grouting effect.

During the process of the shield tunnel advancing, the earth pressure in the bin is supposed to be balanced with that on the excavation face. When the earth pressure in the bin is greater than the earth pressure on the excavation face, it is likely to cause surface uplifting. When the earth pressure in the bin is less than the earth pressure on the excavation face, it may cause the soil near the excavation face move to the tunnel, and then it will lead to the ground subsidence. To simplify the calculation, it is assumed that the earth pressure of the bin is equal to that of the earth pressure on the excavation face of the tunnel. The soil on the excavation face will not produce a longitudinal displacement towards the tunnel, which can be simulated equivalently using Fix command in FLAC3D.

The tunnel excavation function is compiled using Fish programming language. The approximate process is as follows. The stress of a certain thickness of the stratum is released in a certain proportion after the soil excavatedin the tunnel. Then the segment element and slurry element are defined to restrict the longitudinal displacement of the soil on the excavation face of the tunnel. The length of each excavation step is $1.5 \mathrm{~m}$. The project scheme on field is that the the left tunnel was constructed firstly, and then the right tunnel was constructed next.

\section{Results and Discussion}

\subsection{Model validation analysis}

The numerical model was verified by the monitoring results after the construction of the left and right line tunnel, as shown in Fig.3. It can be seen from Fig. 3, the numerical simulation results are basically consistent with the measured values, which indicates the numerical model is reasonable. In addition, it can be seen from Fig. 3(a) that the transverse settlement groove curve of the section approximately conforms to the Gaussian distribution after the construction of the left line tunnel, and the curve is roughly symmetrical according to the axis of the left line tunnel. It can be seen from Fig. 3(b), the curve of the horizontal surface settlement groove is still a single peak settlement curve after the construction of the right line tunnel. The maximum settlement position is close to the surface above the left tunnel axis, but the curve is no longer symmetrical according to the left tunnel axis. Compared with the construction of the left tunnel, the construction of the right tunnel results in a larger maximum ground settlement and a wider settlement groove.

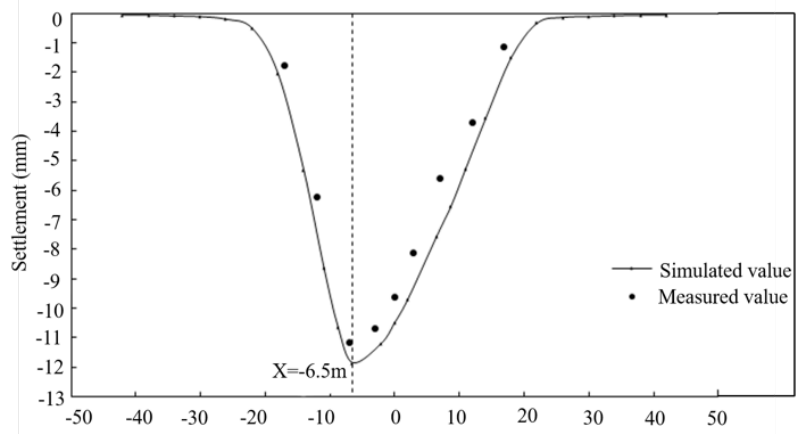

(a) The ground settlement after construction of left tunnel $(x=-6.5 \mathrm{~m}$ is the axis of the left tunnel)

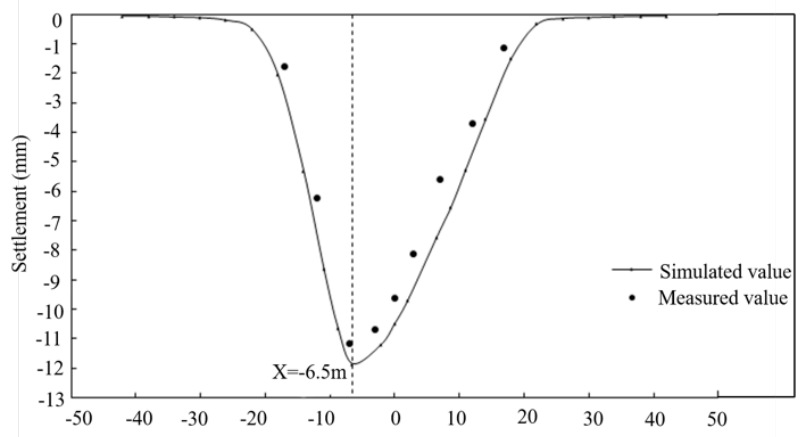

(b) The ground settlement after construction of right tunnel ( $\mathrm{x}=-6.5 \mathrm{~m}$ is the axis of the left tunnel)

Fig. 3. Settlement curves of simulated and measured values.

\subsection{Influence of shield tunnel construction pipeline}

\subsubsection{Influence of shield tunnel construction on ground} settlement above its axis

To study the influence of shield tunnel construction on the surface settlement above its axis, the settlement of each point of the surface is collected every $6 \mathrm{~m}$ (about 1D) of excavation. The settlement curve of the surface above its axis is shown in Fig. 4 when the tunnel has been excavated with different length. 


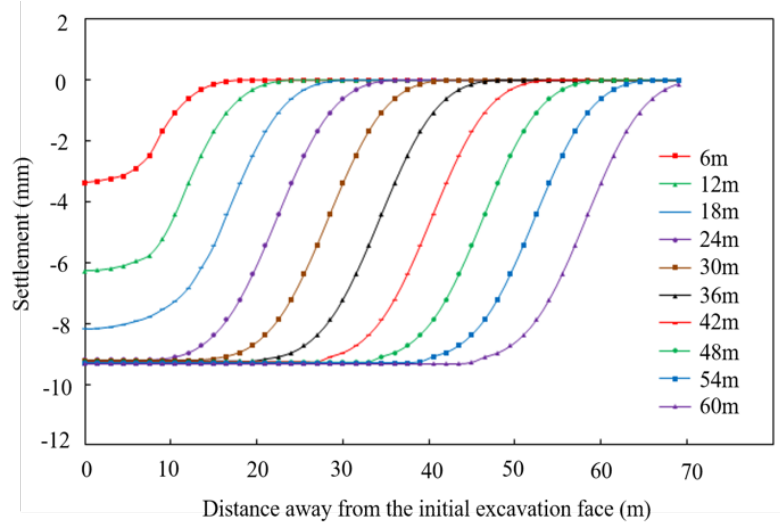

Fig. 4. Ground settlement curve of the surface above the axis of shield tunnel during construction with different excavated lengths.

As can be seen from Fig. 4, the ground settlement above the excavation face is increasing continuously with the shield tunnel moving forward. The ground settlement above the excavation face no longer increases until the distance away from the excavation face is $24 \mathrm{~m}$. The final settlement is stable at about $-9.3 \mathrm{~mm}$.

\subsubsection{Transverse settlement groove of stratum at} different buried depths

As shown in Fig.5, the curve of transverse settlement groove of stratum at different buried depth is approximately Gauss distribution. At the same depth, the settlement of the strata above the axis of the left line tunnel is the largest. The farther the distance of the lateral sides away from the axis, the smaller the settlement. Under different buried depths, the deeper the buried depth and the closer to the tunnel, the larger the width and maximum settlement of its transverse settlement groove. The closer to the axis, the more obvious the settlement difference.

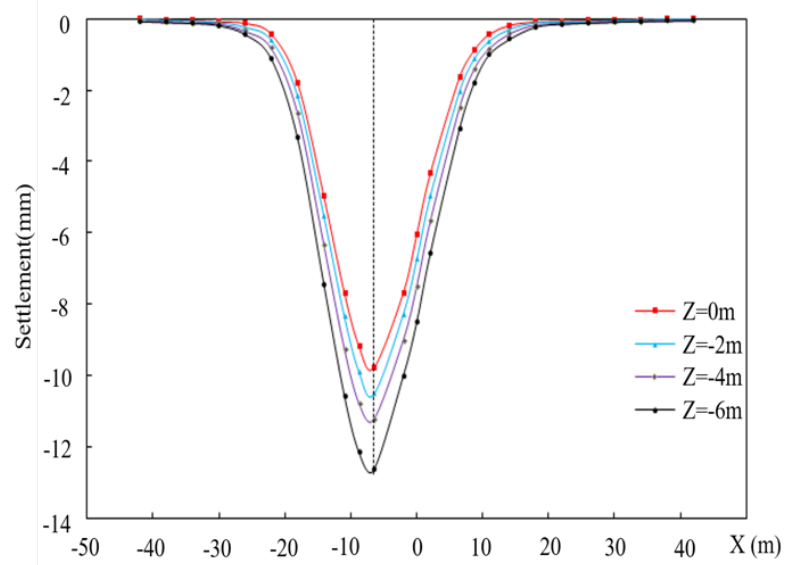

Fig. 5. Settlement groove curves of stratum at different buried depths.

\subsubsection{Influence of shield tunnel construction on pipeline settlement}

The transverse settlement of each point of the pipeline during the construction of the left line tunnel is shown in Fig. 6. The shield tunnel construction has certain influence on the front pipeline. With the shield tunnel moving forward, the settlement of the pipeline above the excavation face increases gradually. The ground settlement above the excavation face no longer increases until the excavation has exceeded $24 \mathrm{~m}$. And the final settlement is stable at -12.8 $\mathrm{mm}$.

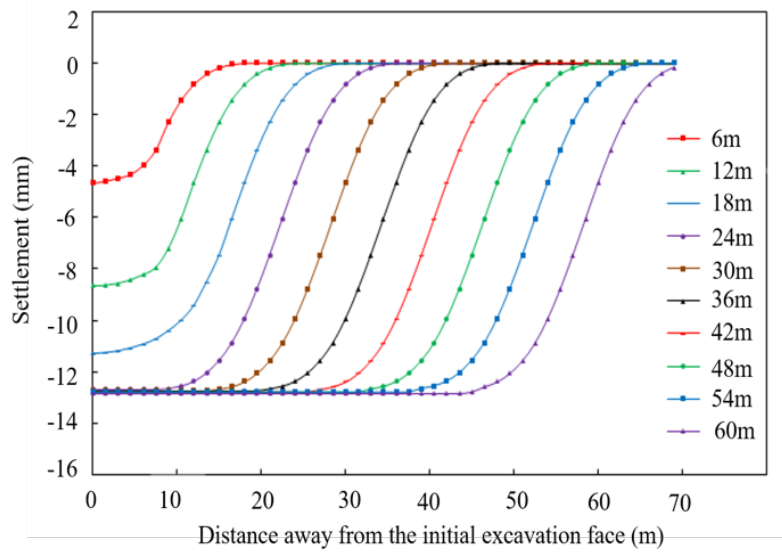

Fig. 6. Settlement curve of pipeline during construction of left tunnel with different excavated lengths.

4.2.4 Influence of shield tunnel construction on the maximum principal stress in pipeline

During the process of shield tunnel construction, the maximum value of the maximum principal stress in the pipeline is recorded every excavation length of $6 \mathrm{~m}$ (about 1D), and its change is shown in Fig. 7. It can be seen from the Fig.7, the maximum principal stress in the pipeline increases continuously during the construction of the left line tunnel. But the extent of increasing is smaller and smaller. When the length of excavation is more than $18 \mathrm{~m}$, the increasing extent of the maximum principal stress is very slow, and the final value is about $0.57 \mathrm{MPa}$. However, the influence of the whole construction process of the right line tunnel on the maximum principal stress of the pipeline is always small, which has been increased to $0.6 \mathrm{MPa}$.

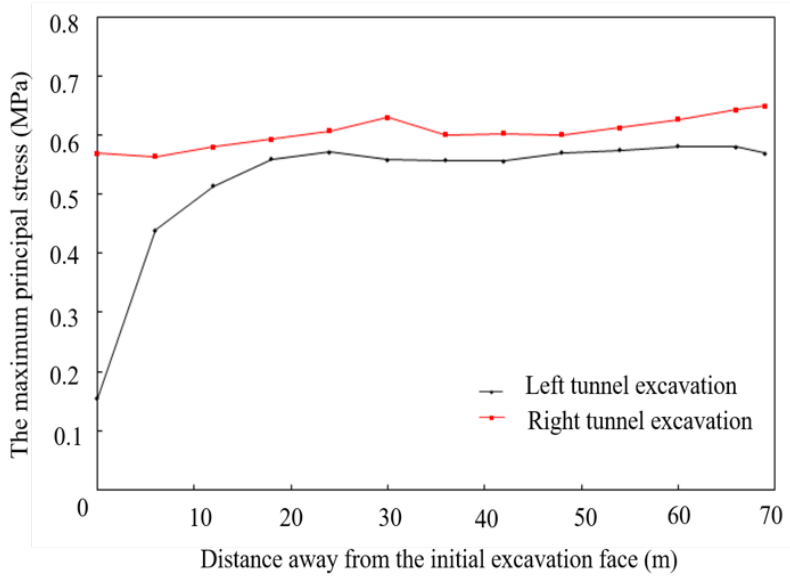

Fig. 7. Maximum principal stress curve of pipeline during shield tunnel construction.

The maximum principal stress in the pipeline is smaller than its allowable stress. But in the actual construction process, the pipeline damage often occurs at the joint, the maximum principal stress in the pipeline may have a greater influence on these parts. Therefore, during the process of shield tunnel construction, we should pay attention to these weak places of pipeline joints. If necessary, it is better to strengthen them in advance to ensure the safety of the pipeline. 


\subsection{Construction schemes analysis}

\subsubsection{Different construction cases}

During the construction of double line tunnel, in order to reduce the interaction effect between the two tunnels, one tunnel is usually constructed firstly. When the distance between the two tunnels exceeds a certain length, or the ground surface above the excavation face of another tunnel is no longer affected by the first tunnel constructed, then another tunnel will be constructed. By this way, not only the period of construction is prolonged, but also the influence on surrounding strata and pipelines is not always the smallest. Therefore, it is necessary to study different construction cases. To analyze the influence of different construction cases on the settlement of surface and pipeline in detail, eleven cases were simulated. The driving direction of all the following cases are same, in which the Case 1 is the same as the actual construction.

(1) Case 1: The left line tunnel was excavated and completed firstly, and then the right line tunnel was excavated.

(2) Case 2: The right line tunnel was excavated and completed firstly, and then the left line tunnel was excavated.

(3) Case 3: The left and right tunnels was simultaneously excavated.

(4) Case 4: The left line tunnel was firstly excavated 4 rings (about 1D), and then the right line tunnel was excavated.

(5) Case 5: The left line tunnel was firstly excavated 8 rings (about 2D), and then the right line tunnel was excavated.

(6) Case 6: The left line tunnel was firstly excavated 12 rings (about 3D), and then the right line tunnel was later excavated.

(7) Case 7: The left line tunnel was firstly excavated 16 rings (about 4D), and then the right line tunnel was later excavated.

(8) Case 8: The right line tunnel was firstly excavated 4 rings (about 1D), and then the left line tunnel was later excavated.

(9) Case 9: The right line tunnel was firstly excavated 8 rings (about 2D), and then the left line tunnel was later excavated.

(10) Case 10: The right line tunnel was firstly excavated 12 rings (about 3D), and then the left line tunnel was later excavated.

(11) Case 11: The right line tunnel was firstly excavated 16 rings (about 4D), and then the left line tunnel was later excavated.

\subsubsection{Comparative analysis of Cases 1,2 and 3}

Under Cases 1, 2 and 3, the horizontal settlement distribution curve of the ground surface after tunnel construction is shown in Fig. 8. It can be seen from Fig. 8 that the horizontal settlement groove curve of the surface is a single peak curve of those three cases, but the location and size of the maximum settlement value are different. The maximum ground settlement caused by Case 3 is close to the ground surface above the symmetrical axis of two tunnels ( $\mathrm{x}$ $=0$ ). The maximum settlement value of Case 3 is the largest among three cases. The place of the maximum ground settlement under Case 2 is close to the right line tunnel axis, and the maximum settlement value is slightly less than that of Case 3. The place of the maximum ground settlement under Case 1 is close to the left line tunnel axis, and the maximum settlement value is the minimum among those three cases.

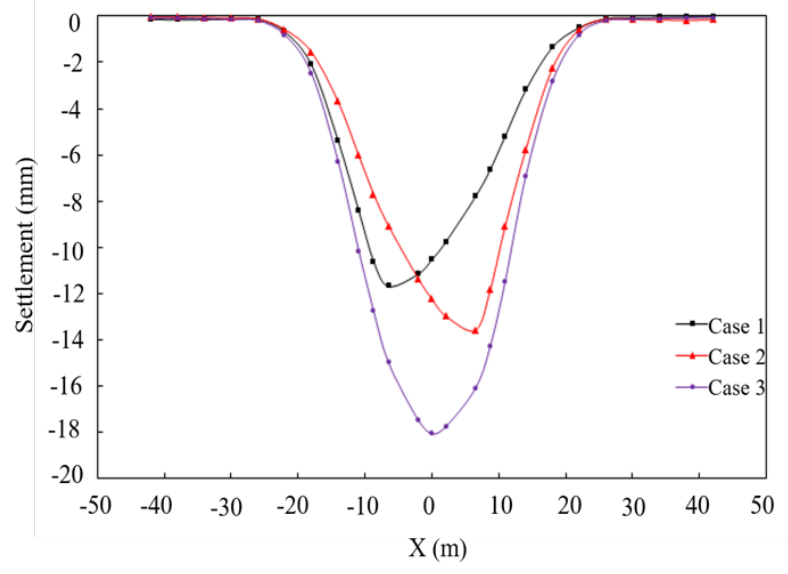

Fig. 8. Settlement of the surface of Cases 1, 2 and 3.

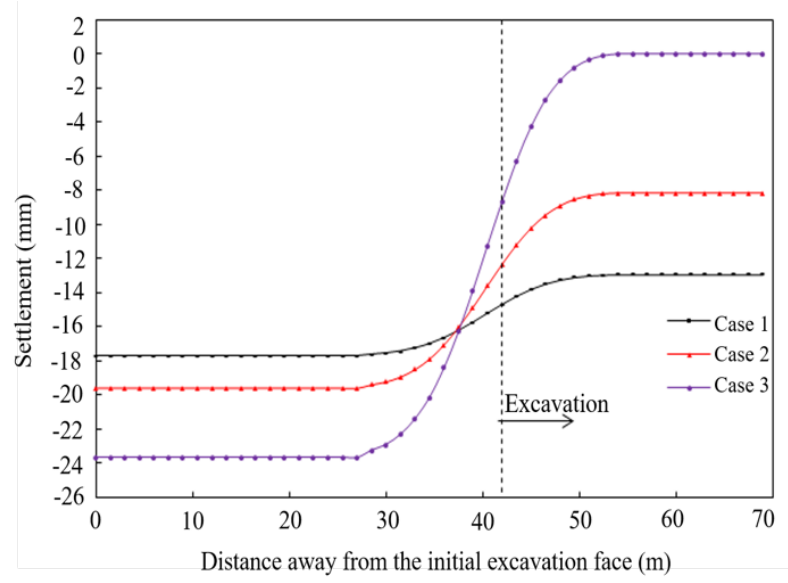

Fig. 9. Settlement of pipeline when tunnel advancing $42 \mathrm{~m}$ of Cases 1, 2 and 3 .

Under those three cases, when the tunnel has been excavated $42 \mathrm{~m}$, the settlement distribution of each point of the pipeline is shown in Fig. 9. It can be seen from the Fig. 9 that the final settlement of pipeline caused by Case 3 is the largest, followed by Case 2, and Case 1 is the smallest. Through the comparison of Cases 1, 2 and 3, it can be known that the Case 1 is much better.

\subsubsection{Comparative analysis of Cases 3, 4, 5, 6 and 7}

Under Cases 3, 4, 5, 6 and 7, the horizontal settlement of the ground surface is shown in Fig.10. It can be seen from the Fig.10 that under these five cases, the horizontal settlement groove curve of the ground surface is also a single peak curve. From Cases 3 to 7, the maximum settlement position of the ground surface tends to move to the left side. Among those five cases, the maximum ground settlement caused by Case 3 is the largest, followed by Cases 4, 5 and 6, and Case 7 is the smallest.

Under Cases 3, 4, 5, 6 and 7, when the tunnel has been excavated $42 \mathrm{~m}$, the settlement distribution of each point of the pipeline is shown in Fig. 11. It can be seen from the Fig. 11 that the final settlement of pipeline caused by Case 3 is the largest, followed by Cases 4, 5 and 6 , and Case 7 is the smallest. Through the comparison of Cases 3, 4, 5, 6 and 7, it can be known that Case 7 is much better. 


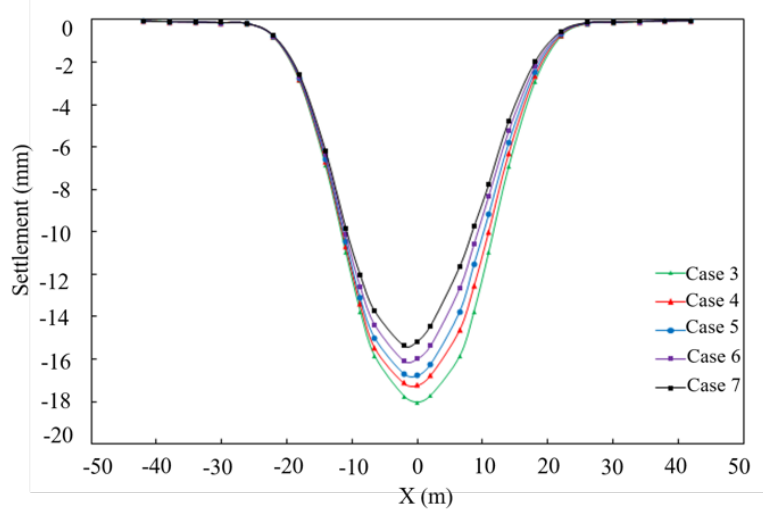

Fig. 10. Settlement of the surface of Cases 3, 4, 5, 6, and 7 .

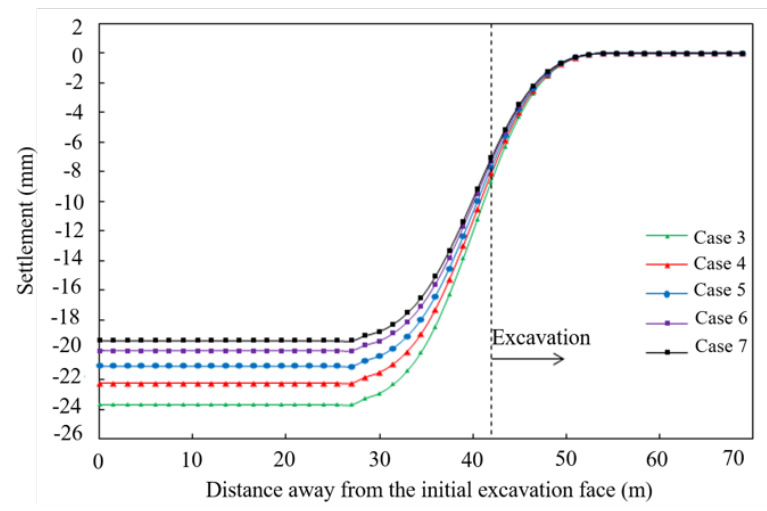

Fig. 11. Settlement of pipeline when tunnel advancing $42 \mathrm{~m}$ of Cases 3 , $4,5,6$, and 7 .

\subsubsection{Comparative analysis of Cases 3, 8, 9, 10 and 11}

Under Cases 3, 8, 9, 10 and 11, the horizontal settlement of the surface is shown in Fig. 12. It can be seen from Fig. 12 that under these five cases, the curve of the horizontal settlement trough on the surface is a single peak curve. From Cases 8 to 11 , the maximum settlement position of the surface tends to move to the right side. Among them, the maximum ground settlement caused by Case 3 is the largest among those 5 cases, followed by Cases 8, 9 and 10, and Case 11 is the smallest.

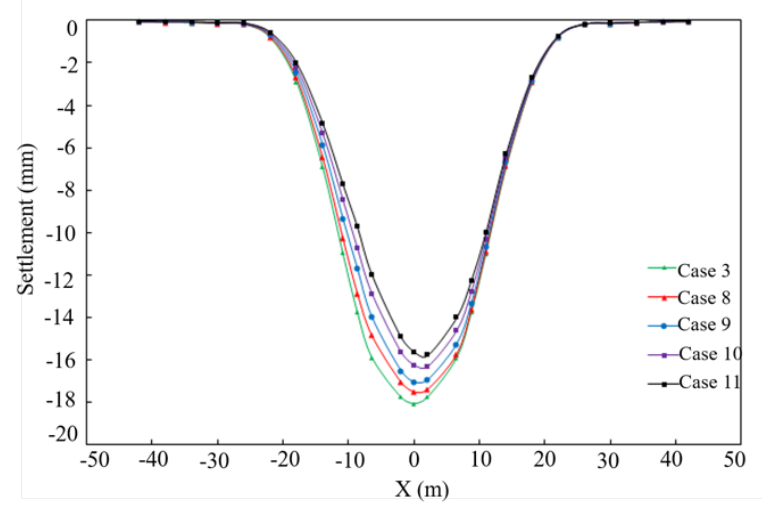

Fig. 12. Settlement of the surface of Cases 3, 8, 9, 10 and 11.

Under Cases 3, 8, 9, 10 and 11, when the tunnel was excavated $42 \mathrm{~m}$, the settlement distribution of each point of the pipeline was shown in Fig. 13. It can be seen from Fig. 13 that the final settlement of pipeline caused by Case 3 is the largest, followed by Cases 8,9 and 10 , and Case 11 is the smallest. It can be known that Case 11 is much better.

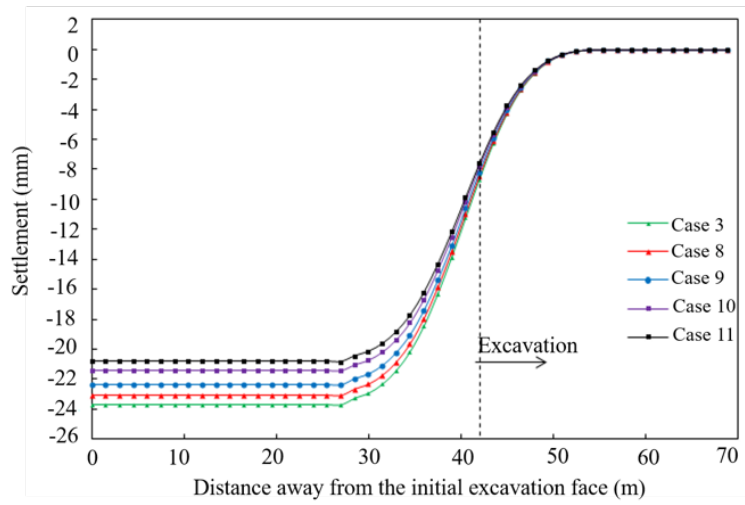

Fig. 13. Settlement of pipeline when tunnel advancing $42 \mathrm{~m}$ of Cases 3, $8,9,10$ and 11 .

By comparing Cases 1, 2 and 3, the surface and pipeline settlement caused by Case 1 is the smallest. By comparing Cases 3, 4, 5, 6 and 7, the surface and pipeline settlement caused by Case 7 is the smallest. By comparing Cases 3, 8, 9, 10 and 11, the surface and pipeline settlement caused by Case 11 is the smallest. The maximum ground settlement value caused by Cases 1,7 and 11 is $-11.67 \mathrm{~mm},-15.36 \mathrm{~mm}$ and $-16.02 \mathrm{~mm}$, respectively, and the final pipeline settlement is $-17.70 \mathrm{~mm},-19.35 \mathrm{~mm}$ and $-20.82 \mathrm{~mm}$, respectively. The results showed that the ground and pipeline settlement caused by Case 1 is the minimum. Therefore, the construction sequence of Case 1 is the most reasonable, that is, the left line tunnel should be excavated firstly, and the right line tunnel is excavated later after the left line tunnel completed. If the two tunnels were needed to excavate simultaneously, the right line tunnel was better constructed after the left line tunnel had excavated larger than 16 rings (approximately 4 times diameter of tunnel).

\section{Conclusions}

To ensure the stability of the pipeline during the shield tunnel construction, based on the urban metro tunnel in Zhengzhou, the influences of different construction schemes on the response of pipeline were analyzed by using simulation method, some conclusions werw drawn as follows.

(1) With the shield tunnel moving forward, the settlement of the surface and pipeline above the excavation face increases gradually. The settlement of the surface and pipeline above the excavation face no longer increases until the shield machine has excavated $24 \mathrm{~m}$. And the final settlement of ground surface and pipeline is stable at -9.3 $\mathrm{mm}$ and $-12.8 \mathrm{~mm}$, respectively.

(2) During the construction of the left line tunnel, the maximum principal stress of the pipeline increases continuously, but the increasing range is smaller and smaller. When the excavation length has exceeded $18 \mathrm{~m}$, the maximum principal stress changes slowly and is stable at about $0.57 \mathrm{MPa}$. The influence of the construction of the right line tunnel on the maximum principal stress of the pipeline is always small, which only increases to $0.6 \mathrm{MPa}$.

(3) Based on the comparative analysis of the surface and pipeline settlement caused by 11 different cases, it is found that Case 1 is the most reasonable, that is, the left line tunnel is excavated firstly and the right line tunnel is excavated later after the left line tunnel completed. If the two tunnels were needed to excavate simultaneously, the right line tunnel was better constructed after the left line tunnel had 
X.M. Guan, G. Wang, X.C. Wang, J.Y. An, H.B. Lei and W.Z. Guan/

Journal of Engineering Science and Technology Review 13 (2) (2020) 167 - 173

excavated larger than 16 rings (approximately 4 times diameter of tunnel).

These conclusions can provide a reference for the similar shield tunnel construction engineering, but for the new challanging conditions, it needs to be further studied.

\section{Acknowledgements}

This work was supported by the National Natural Science Foundation of China (51708317; 51978356), Key Research and Development Plan of Shandong Province (2019GSF111027), the Taishan Scholar Priority Discipline
Talent Group program funded by the Shan Dong Province, and first-class discipline project funded by the Education Department of Shandong Province (2019), the academic project of China Construction Second Engineering Bureau LTD. (91110000100024296D170006).

This is an Open Access article distributed under the terms of the Creative Commons Attribution License

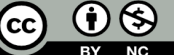

\section{References}

1. Shuren Wang, S. R., Shi, K. P., Chen, W. X., Liu, S. P., "Stability analysis of middle rock pillar and cross-section optimization for ultra-small spacing tunnels". Journal of Engineering Science and Technology Review, 11(3), 2018, pp. 147-153.

2. Shuren Wang, S. R., Shi, K. P., Li, Z. H., Li, Z. C., Wang, Y. F., "Spatial distribution law of vibration acceleration of ultra-smallspacing tunnel under train moving loads". Journal of Engineering Science and Technology Review, 12(6), 2019, pp. 96-104.

3. Bobet, A., "Analytical solutions for shallow tunnels in saturated ground". Journal of Engineering Mechanics, 127(12), 2001, pp. $1258-1266$

4. Gonza, L. C., Sagaseta, C., "Patterns of soil deformations around tunnels: application to the extension of Madrid Metro". Computers and Geotechnics, 28(6/7), 2001, pp. 445-468.

5. Verruijt, A., Booker, J. R., "Surface settlements due to deformation of a tunnel in an elastic half plane". Géotechnique, 46(4), 1996, pp. 753-756.

6. Chou, W., Bobet, A., "Predictions of ground deformations in shallow tunnels in clay". Tunnelling and Underground Space Technology, 17(1), 2002, pp. 3-19.

7. Park, K. H., "Analytical solution for tunnelling-induced ground movement in clays". Tunnelling and Underground Space Technology, 20(3), 2005, pp. 249-261.

8. Park, K. H., "Elastic solution for tunneling-induced ground movements in clays". International Journal of Geomechanics, 4(4), 2004, pp. 310-318

9. Sagaseta, C., "Analysis of undrained soil deformation due to ground loss". Géotechnique, 37(3), 1987, pp. 301-320.

10. Loganathan, N., Poulos, H. G., "Analytical prediction for tunnelinginduced ground movement in clays". Journal of Geotechnical and Geoenvironmental Engineering, 124(9), 1998, pp. 846-856.

11. Wei, G., Pang, S. Y., Zhang, S. M., "Prediction of ground deformation induced by double parallel shield tunneling". Disaster Advances, 6(13), 2013, pp. 91-98.
12. Wei, G., Pang, S. Y., "Study of three-dimensional soil deformation caused by double-line parallel shield tunnel construction". Rock and Soil Mechanics, 35(9), 2014, pp. 2562-2568.

13. Chen, R. P., Zhu, J., Liu, W., Tang, X. W., "Ground movement induced by parallel EPB tunnels in silty soils". Tunnelling and Underground Space Technology, 26(1), 2011, pp. 163-171.

14. Hisatake, M., "A proposed methodology for analysis of ground settlements caused by tunneling, with particular reference to the "buoyancy" effect". Tunnelling and Underground Space Technology, 26(1), 2011, pp. 130-138.

15. Ouyang, H., Wang, T., "Safety judgment of underground pipeline affected by tunnel construction", Hunan Transportation Science and technology, 35(1), 2009, pp. 127-129.

16. Zhang, C. R., Yu, J., Huang, M. S., "Analysis of the influence of tunnel excavation on the buried pipeline near the discontinuous interface", Journal of geotechnical engineering, 35(6), 2013, pp. 1018-1026.

17. Klar, A., Vorster, T. E. B., Soga, K., Mair, R. J., "Soil-pipe interaction due to tunneling: comparison between Winkler and elastic continuum solutions", Géotechnique, 55(6), 2005, pp. 461466.

18. Vorster, T. E., Klar, A., Soga, K., Mair, R. J., "Estimating the Effects of Tunneling on Existing Pipelines", Journal of Geotechnical \& Geoenvironmental Engineering, 131(11), 2005, pp. 1399-1410.

19. Li, X. G., Wang, T., "A simple method for safety assessment of flexible pipelines", Geotechnical Mechanics, 29(7), 2008, pp. 18611864.

20. Wu, X. G., Zeng, T. M., Zhang, L. M., Song, R. X., "Study on safety risk management of adjacent pipelines in metro construction". Journal of Railway Engineering Society, 30 (9), 2013, pp. 127-132 